\title{
Improving Laboratory Experiences in Engineering Education
}

\author{
S. S. Rathod ${ }^{1}$ and D. R. Kalbande ${ }^{2}$ \\ ${ }^{1}$ Professor and Head Electronics Engineering Department \\ ${ }^{2}$ Professor and Head Computer Engineering Department \\ Sardar Patel Institute of Technology, Munshi Nagar, Andheri (W), Mumbai-400058 \\ ${ }^{1}$ surendra_rathod@spit.ac.in \\ 2drkalbande@spit.ac.in
}

\begin{abstract}
Laboratory classes are integral part of an engineering course. Laboratory sessions are primarily designed to develop proficiency in technical skills, provide an opportunity to place theory in context, develop critical thinking skills and promote enquiry based learning. Laboratory experiences will be paramount in developing our students as independent learners, researchers, critical thinkers and generators of knowledge. There are several reforms need to be implemented to improve student laboratory experiences. This paper suggests some of the methods that can be implemented in engineering institutes. This paper also presents the study of usage of online tools and rubric based laboratory assessment methodology adopted in electronics engineering course.
\end{abstract}

Keywords: ICT, laboratory, teaching learning, outcome based and innovation

\footnotetext{
S. S. Rathod ${ }^{1}$

${ }^{1}$ Professor and Head Electronics Engineering Department

Sardar Patel Institute of Technology, Munshi Nagar, Andheri (W), Mumbai-400058

${ }^{1}$ surendra_rathod@spit.ac.in
}

\section{Introduction}

A laboratory is a very important component in engineering education. Laboratories foster a range of skills including communication, knowledge, teamwork, ethics, and encouraging information acquisition and are used to support learning in lectures by enhancing student understanding of theoretical concepts. There is no ambiguity in realizing the importance of laboratories in engineering education. All courses must be supported with lab modules as far as possible. Students cannot learn how to test circuits without going to a laboratory, just as human beings cannot learn how to swim without diving into the water [1]. However, conventional engineering laboratory strategies are not sufficient to meet course outcomes. It is very challenging to design laboratory courses which will motivate students to spend more time on experimentation and improve their learning.

In traditional laboratory a student follow a given procedure to obtain pre-determined outcome. This allows student to manipulate equipment, learn standard techniques, collect data, interpret data and write report. However, the level of critical thinking required to perform an experiment and consequently the deep learning achieved is low. Furthermore, co-operative learning between instructor and student is not facilitated in traditional lab methods. A more ideal approach is required that integrates application of knowledge to solve problems, group work, and an opportunity to design experiments, including consideration of safety aspects. [2] [3]

Student satisfaction level must be at the core of the improvement in laboratory experience that must be recorded and analyzed for corrective actions. Increasing the level of student satisfaction can benefit student learning. It has to be recognized that for students to obtain the necessary laboratory skills to use lab facilities effectively requires a significant commitment of time for both the instructor and the student.

The goals for improvement in laboratory experiences are enhancing understanding of course matter, developing 
teamwork abilities, developing practical skills, developing scientific reasoning, understanding the complexity and ambiguity of the empirical work and cultivating the interest in learning. Primarily it is an improvement with regard to conducting an experiment, recording observations and analyzing an experimental data [4].

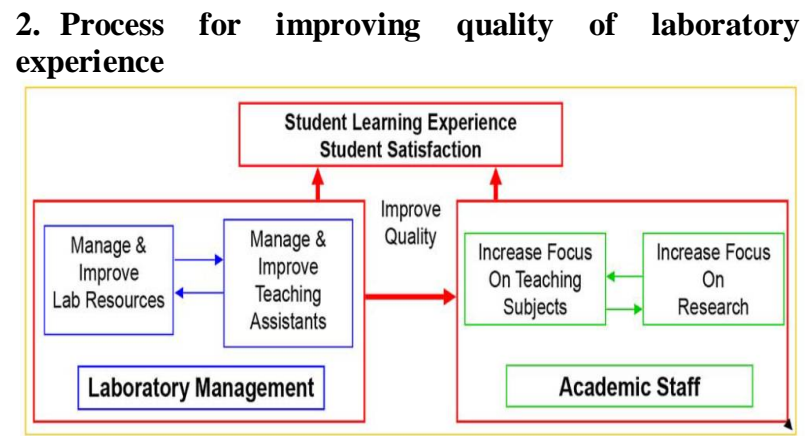

Fig. 1 Laboratory Learning Model [5]

Exceeding student's expectations does not happen by mistake, it must be deliberately managed by someone in the programme [5]. There have been a number of studies [5] looking at laboratory management and how it can be used to manage quality, safety, and resources effectively. Laboratory learning model [5] shown in figure 1 can be adopted to improve the quality of learning. It is hard to manage and ensure quality with so many laboratory-based courses. There are several course co-ordinators, labincharges and various laboratories distributed in the department and sometimes inter-department for interdisciplinary courses. The effective co-ordination between various laboratory in-charges is required which can be fulfilled by having a 'Laboratory Manager' at the department level who can be made accountable [5]. To manage the conflicting needs of software, Open source or proprietary, choice of the equipments etc. can be managed at by lab manager. The Laboratory Manager would work together with course coordinators and technical staff to coordinate any improvements to each laboratory identified via the student/instructor surveys. It is necessary that the Laboratory Manager must work closely with laboratory incharges and course coordinators to implement necessary improvements.

Figure 2 show the process for improvement in the laboratory experiences of students. There are various novel methodologies as a input to the process which are explained in the following sections. We need to identify student's requirements and their abilities to perform the experiment. For example, differently abled student can be instructed in a different manner as compared to the normal student. We need to ensure that all students including students with disabilities have equal access to educational opportunities. Services for students with disabilities should be implemented in laboratories like extended time, the use of an assistive listening device, alternative media, peer advisors, disability-related equipment, and handbook for students with disabilities. Safety guidelines and emergency evacuation procedures need to be given and explained to these students. Feedback collection is a driving factor for any improvement. Feedback about the overall student learning experiences in the form of satisfaction level from

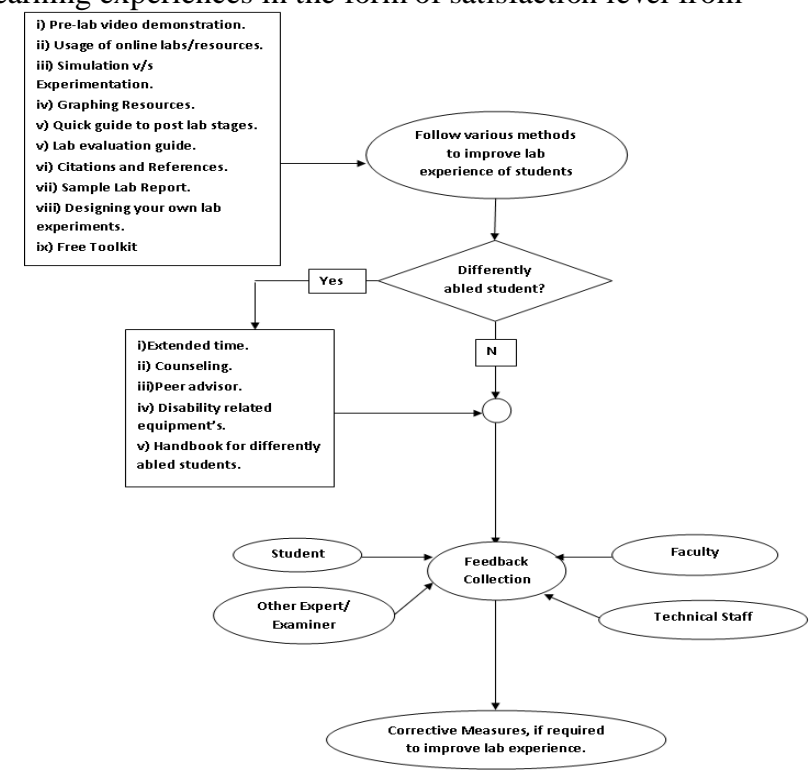

Fig. 2 Process for Improving the Laboratory Experiences

the students, faculty members, technical staff and other experts should be collected and analyzed for the corrective action.

\section{Manage and Improve Lab Design}

Design of laboratory and appropriate experiments require significant of quality time. However it is at the core of the improvement in the experimentation. Design of an experiment plays a major role in student satisfaction level. In the design of an experiment, the amount of time required to complete the tasks should be carefully considered. It is better for the student to undertake less activity but clearly understand the concepts behind the activity than undertake more work and have no understanding. Following are the various ways of designing laboratories.

A. Simulation versus experimentation: There are numerous uses of simulation in the laboratory. Simulations can be used as a pre-lab experience to give students some idea of what they will encounter in an actual experiment. This can improve laboratory safety by familiarizing students with the equipment before actually using it. It also can result in significant financial savings by reducing the time a student or team needs on real - and expensivelaboratory equipment, thereby reducing the number of laboratory stations required. Simulations can be used as stand-alone substitutes for physical laboratory exercises. Simulations are also useful for experimental studies of systems that are too large, too expensive, or too dangerous for physical measurements by undergraduate students.

TCAD (Technology for Computer Aided Design) tools are introduced from the second year electronics engineering course 'Electronic Devices'. It has been observed that it gives more understanding of the concepts like band diagrams and electric fields in devices. The use of TCAD tools allows students to learn the fundamentals of device processing in a virtual environment and helps them to 
acquire critical thinking skills while having an authentic design experience (very similar to the actual experience in research or work environments) [6]. Proficiency with the use of TCAD tools has become a necessity in modern manufacturing environments, particularly in semiconductor industry. Introducing TCAD tools also better prepares students for semiconductor device research in advanced courses.

B. Student Solving Challenging Problems by Designing Experiments: Instead of following an established procedure given in laboratory manual, student will be given a scientific problem and will be able to design his/her own way of solving the problem. The problem statement should be put challenges to the students. Student involvement in the laboratories increases if the experiments are designed and executed by the students themselves.

C. Mini-Projects: Project-based learning motivates students to learn actively, so it can be widely applied to many engineering courses [7]. Mini-projects provide opportunities for the students to develop project management skills while working in a team. The group work is important to prepare students for employment and to overcome socio-economic barriers.

D. Optional Experiments: Students are required to select one of the three optional laboratory experiments relating to their field of interest upon successful completion of the mandatory experiments. Thus experiments designed for a particular course should be more than the minimum required experiments.

E. Course based independent development of laboratory: There are several case studies [6][8][9] [10][11][12][13] published on the implementation of laboratory courses e.g. on Wireless communication, analog circuits, microelectronics etc. Course level improvements can be done by adopting suggested methods in these studies.

\section{Manage and Improve Lab Resources}

A. Manage and Improve Teaching Assistants: Demonstrating in a laboratory is very different from teaching in a lecture or tutorial, as a wider range of skills are needed. Demonstrators need to know how to teach, manage students, use instruments, monitor lab safety, and most importantly know how to troubleshoot in electronics engineering related courses [14]. Many of the demonstrators had strong theoretical knowledge but were severely lacking in terms of practical skills. This problem needed to be rectified, because the laboratory is important for the development of hands on skills, and it was unacceptable to have demonstrators lacking these fundamental skills [14]. Regular training programmes should be organized on how to use the equipment in the laboratory, as well as an understanding of how to correctly troubleshoot problems.

B. Free toolkit to each student: For conducting experiments of various subjects in Electronics Engineering Department students regularly need breadboard, soldering gun, multimeter, connecting wires etc. To effectively implement the theory of 'one student one experiment' and every student to perform experiment independently; a scheme proposed and implemented in 2013-14 through which every student gets one free kit consisting of the above parts. The following are the benefits observed by starting this scheme:

1. Students need not issue every time they come to lab and hence it saves their time.

2. Students mount the components in their free time and test circuits (even at home)

3. During their entire undergraduate study they carry the same kit and perform experiments. It has enhanced their capabilities in using breadboard and multimeter.

4. If experiment remains incomplete in allotted time then they can continue in the next session and need not mount the circuit again. Hence it is possible to perform experiments which may take more than one turn. This saves student time significantly. Students also troubleshoot in free time or at home. Teachers can also give big circuits for testing.

5.This scheme found to be helpful during final year projects and mini projects.

6.Students became more disciplined do not damage equipments.

7.It also saves the time of technical assistants.

C. Use of Moodle (Modular Object-Oriented Dynamic Learning Environment): Moodle is one of the popular open source tool used to manage learning resources. Now a day's educator's job is changed from being 'the source of knowledge' to being an influencer and connecting with students in a personal way that addresses their own learning needs, and moderating discussions and activities in a way that collectively leads students towards the learning goals. A healthy amount of connected behavior within a learning community is a very powerful stimulant for learning, not only bringing people closer together; but promoting deeper reflection and reexamination of their existing beliefs [15][16]. These can be implemented in laboratory experiments as well via moodle. The college students believed that Moodle is very effective tool through gathering of knowledge via uploaded handouts and upholding discipline via time management.

D. Use of Mobile Phones in Laboratories: Through mobile technology we can better engage students and help improve their performance in laboratories. Mobile technology is impacting nearly every aspect of our lives, and the way we learn and teach is no exception. These technologies can level the playing field in laboratory, and give children from families of all economic backgrounds an opportunity to learn in the same way and compete on a more even level. This is also true for students who come from low-income households - many families do not own a computer, but they have mobile devices.

It is no longer adequate to teach students the way we were taught. First, let students use mobile devices in the laboratory sessions because they are already using them every day on their own. We need to provide kids with 
opportunities to work through real-world problems using the mobile technology they know so well. Learning about sound waves and wave frequencies by reading about them in a textbook or simulating a circuit using an online oscilloscope program? I know which one my students would choose. Students today, regardless of socioeconomic background, are 21st century learners. Mobile technology is a way to capture and sustain their interest in laboratories, so that they become the innovators. All students will enjoy the use of app for instructions and feedback on their smartphones and teacher will immediately get response. Students shift from being dependent to being independent information seekers. Figure 3 show that mobile app can be used for the simulation of an electronic circuit in a VLSI design course.

A primary disconnect is the fact that many teachers just do not know how to use mobile devices as an education tool. Teachers must embrace mobile technology, just as our children and every major business sector and industry have. Case in point from one of my students, who said he does not just use technology for playing games, texting friends and viewing YouTube. He uses his smart phone to take notes, do research and stay organized and it has helped improve his grades, his behavior and his outlook on his future. Finding information in this manner is a very important skill for engineers to have, and learning should always encourage this independent searching.

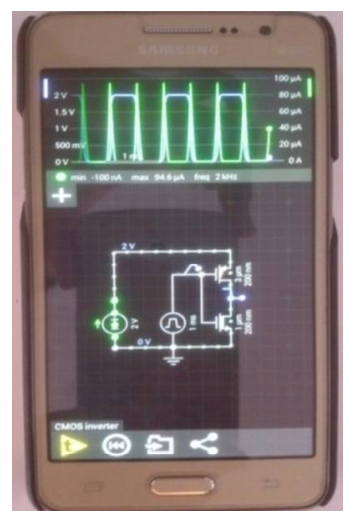

Fig. 3 Use of mobile phone to simulate electronic circuit in a VLSI Design Course

E. Using Online Resources like nanoHUB.org: A substantial amount of resources is currently available on the internet that is free and useful in teaching skills used in the laboratory. NanoHUB.org [17] [18] provides computational resources available as online research and education platform. Computational resources available in the nanoHUB.org have been incorporated as part of the practical laboratory exercises in course "IC Technology" for semester VII. The experiments carried out during the course allowed students to enhance their understanding of those theoretical concepts dealing with Nanoelectronic materials and devices, thus becoming more motivated and satisfied. One of the most successful examples of using elearning methodologies is nanoHUB.org. From a pedagogical perspective, and even though nanoHUB.org is very well organized and managed, it is important to guide students in order to help them browsing through the enormous amount of multimedia data they can access.

F. Virtual Remote Laboratory: Virtual and remote laboratories are e-learning resources that enhance the accessibility of experimental setups providing a distance teaching framework which meets the student's hands-on learning needs [19]. In addition, online collaborative communication represents a practical and a constructivist method to transmit the knowledge and experience from the teacher to students, overcoming physical distance and isolation [20]. Students must carry out their practical activities in an autonomous way and therefore, if teachers want to facilitate their work, complementary web-based resources like Moodle to the virtual labs should be included. Labview based remote triggered virtual laboratories can be developed. That means students can not only simulate virtual outcomes of experiments, but also control real instruments while they are located elsewhere [21]. Remote Triggered Virtual Labs experiments enhance both theoretical and practical learning experience using real time data streaming and analysis. Real time data streaming includes plotting laboratory experiment data values to the user, showing trigger and control buttons and signals and live video streaming of the respective experiment.

G. Prelab video demonstration: Laboratory experiments are usually created with the understanding that students have already obtained a satisfactory level of pre-requisite knowledge in the use of various hardware and software. These presumptions, however, can cause significant stumbling blocks for students without these skills. The use of multimedia and online technologies can help bridge the gap with deficiencies in required knowledge. Helps students think about the lab scientifically before they do the lab. There is increasing evidence that prelab sessions are beneficial to the student learning. It increases confidence to carry out the activities during lab sessions. In particular developing video resources can be time consuming, but beneficial for learning. Videos may contain the information regarding history/background of equipment, applications/use in industry, description/parts, operating principles, variations of instrument, capabilities and limitations, advantages and disadvantages, possible errors in using, maintenance and care, safety precautions and equipment demonstrations along with the course content.

H. Networking Environment in the Lab: Networked environment can give access an immediate data and instructor is able to make available resources immediately to all the students during lab sessions. The networked architecture of the laboratory permits the centralized supervision and tracking of the work done at each bench [22].

I. Help Improving Laboratory Report: Helpful hints on following points on how to improve each component of the lab can be provided through manual.

1. Improving the title of the experiment e.g. title should be a complete sentence and should carry enough information. 
2. Improving the presentation of report i.e. correct format of tables and figures, correct grammar and spelling, and scientific style of writing.

3. Introduction section must define the problem statement, establish scientific concept, and provide logical reasoning.

4. Results must begin with effective statements of overall findings and results must be presented visually, clearly and accurately. Conclusion section must convincingly describe what has been learned in the lab, whether expected outcomes are met or not. It should provide sound judgment based on the evidences. Clear evidence to judgment must be provided in the findings and how evidence contributed toward judgment must be able to show. Primarily student is able to establish the science behind the experiment. That is, laboratory procedure is expected to yield certain results and to a certain extent, the quality of the experiment depends on whether or not those results are obtained. One should be able to clearly relate the theory with the laboratory findings.

5. Report must list all appropriate sources of references. Student must back up the findings with the appropriate references. Lab report must allow thoughtful scientific inquiry and student's ability to do that. In other words, through lab report student need to show that he is an independent thinker as an engineer.

6. Report must provide an opportunity to compare your results to the results of others, other students in the lab or published scientific studies. Teacher can present comparison of results obtained by various students at the end of the lab session. This is an important aspect of scientific inquiry. Post lab session or 'wrap-up' session are an effective means of concluding a learning exercise and useful to provide feedback.

\section{J. Other Resources to be Provided for Improving} Laboratory Experience:

Graphing Resources: Students are expected to know how to record and present data. Various kinds of graphic resources can be provided.

Lab Guide: Guide students in collecting, managing and analyzing data. A hard-copy form to print out and bring to the lab and answer InLab questions by hand.

Quick Guide to Post Lab Stages: An abbreviated version of the Post-Lab stages to be used as a quick reference guide. Leads students step by step in writing lab report.

Lab Check lists: A checklist of the elements that need to be in an effective lab report. This directs students in improving their lab reports.

Lab Evaluation Guides: Criteria that instructors will be using to grade lab reports

Online Writing Handbook: Web sites to help you with questions about grammar, style, punctuation, mechanics, using the internet, search engines, and much more
Citations and References: Advice on citing information from outside sources in the body of the report and listing those sources of information in the References along with the availability of references.

Sample Lab Reports: Sometimes it's helpful to be able to see what a good lab report looks like.

\section{Improvement in Laboratory Assessment}

Firstly incorporate novel assessment methods, including student led laboratories, in-house produced instructional videos, audience response devices and pre-practical online multiple choice questionnaires (MCQ). Secondly encourage an improved culture of feedback and develop timely feedback mechanisms, including peer review, tutor face-toface and audio feedback, online automatic feedback and report checklists. Finally embed transferable skills into the laboratory including group work, communication skills, organization and project planning, health and safety [2][8].

A. Assessment with Rubrics: A redesigned assessment strategy was implemented to target the problem areas of scientific observation and report writing. The instructional material was prepared to help student to construct their own learning. Table I show the assessment Rubrics for the laboratory course implemented in electronics engineering department. This placed a higher emphasis on continual assessment with Rubrics through a constructive writing accompanied by formative and constructive feedback.

B. Peer Evaluation: Each team member evaluated the other fellow team members on their contributions to the five problems. A student did not have to evaluate himself. Each team member had to give one of the evaluation level e.g. contribution above team norms, as per team norms, below team norms and no contribution, to every other member of his or her team.

C. Industry Feedback: The goal of industry survey is to find out the relevance of the contents of the lab course to the industry [23]. Incorporate suggestions from the industry personals into lab.

\section{Results and Key Findings}

\section{A. Students' experience with nanoHUB.org:}

The following experiments were conducted on nanohub for 'IC Technology' course.

1. Simulation of oxidation process with Deal-Grove model for different conditions (e.g. oxidation type, orientation, time, temperature, thickness etc.) (Tool: a TCAD lab on nanohub.org)

2. Simulation of diffusion process for different conditions (e.g. source, time, temperature, dopant etc.). (Tool: a TCAD lab on nanohub.org)

3. Simulation of PN junction for various structure and environmental conditions. Repeat the entire simulation for Ge diode. (Tool: a TCAD lab on nanohub.org)

4. Simulation of MOS capacitor (Classical Simulation) for single gate device for a typical value of fixed charge 
density and interface trap charge density in gate insulator. (Tool: a TCAD lab (MOSCap) on nanohub.org)

5. Simulation of MOS capacitor (Quantum Simulation) for single gate device for a typical value of fixed charge density and interface trap charge density in gate insulator. (Tool: a TCAD lab (schred) on nanohub.org)

6. Simulation of $n$ type and $p$ type MOSFETs (bulk, SOI and Double Gate) to obtain family of ID-VG and ID-VD characteristics. (Tool: a TCAD lab on nanohub.org)

7. Simulation of field effect mobility of a back-gated CNTFET device using $\mathrm{SiO} 2$ as the gate dielectric. Obtain results for Field Effect Mobility, Density of States and Overall Conductance. (Tool: CNT Mobility on nanohub.org)

8. Simulation of Carbon Nanotube MOSFET for different conditions (e.g. gate/drain voltage sweep, threshold voltage etc.). (Tool: FETToy on nanohub.org)

9. Simulation of Silicon Nanowire MOSFET for different conditions (e.g. gate/drain voltage sweep, threshold voltage etc.). (Tool: FETToy on nanohub.org)

10. Simulation of SOI and Double Gate MOSFET with drift diffusion transport model and constant mobility model. (Tool: NanoMOS on nanohub.org)

11. Simulation of FinFET to plot energy band diagram and IV characteristics for different values of gate and drain bias. Comment on the results obtained. (Tool: MuGFET on nanohub.org)

For each experiment, students reported the resources available in nanoHUB.org, such as presentations, course notes, CAD simulation tools, animations, learning modules, bibliographical references, links to pages, etc. Students attending these experiments were surveyed in order to give us their feedback to improve the quality of the course in terms of contents, learning resources and pedagogic procedures. As shown in figure 4, majority of the students are interested, motivated and satisfied with the use of nanohub. Also as shown in figure 5, majority of the students strongly agree that their laboratory experience is improved with the use of nanohub.

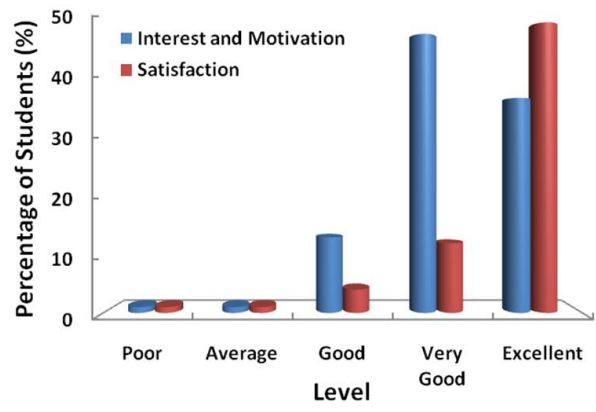

Fig. 4 Student feedback about nanohub

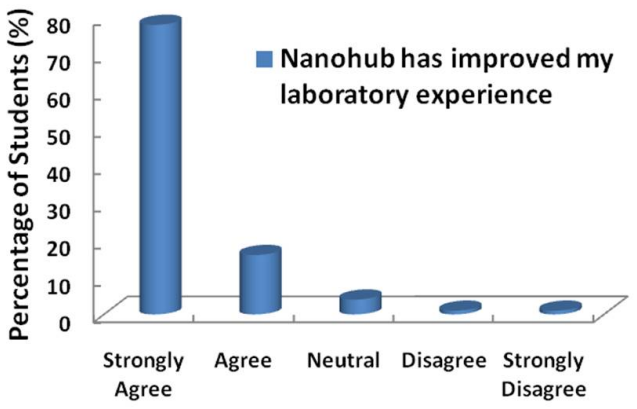

Fig. 5 Student feedback about improvement in learning

\section{B. Experiences of assessing with Rubrics:}

Feedback from students and staff indicate that Rubrics is an effective resource that has enhanced involvement of students and learning in the laboratory. Every student is graded as per the Rubrics shown in Table I. Also every student being given the feedback about his/her performance in the mid-semester as well as at the end-semester in writing based on the performance indices. Thus every student knows what are his strengths and where is the scope for improvement.

Figure 6 show student's performance after implementing performance indices. It is found that first time in 2012-13 when performance indicators were implemented in laboratory for the assessment, students did not take it seriously and hence their attainment was very less. However, when students realized that these performance indices are affecting grades, they took it seriously from the next year. Now significant improvement in the laboratory sessions can be observed particularly with respect to some of the performance indices. But preparedness for the laboratory session is somehow students are not able to demonstrate upto the mark. Also feedback from the faculty who are using as well as who are not using (but know about it) is taken and the results are shown in figure 7. Still it has been observed that some of the faculty members are reluctant to introduce them in courses. This can be attributed to the time required for the assessment of all the students is significant. However, those who have adopted these Rubrics they are satisfied with the level of improvement observed in students.

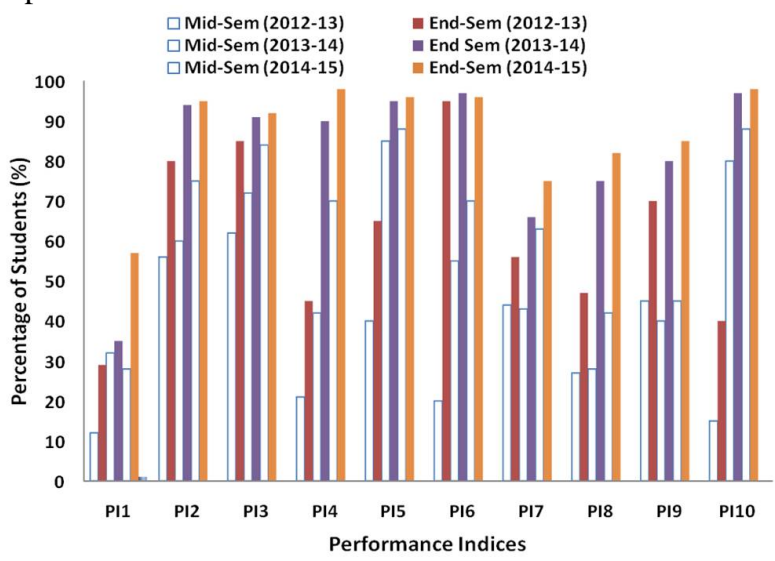

Fig. 6: Student's performance after implementing performance indices 


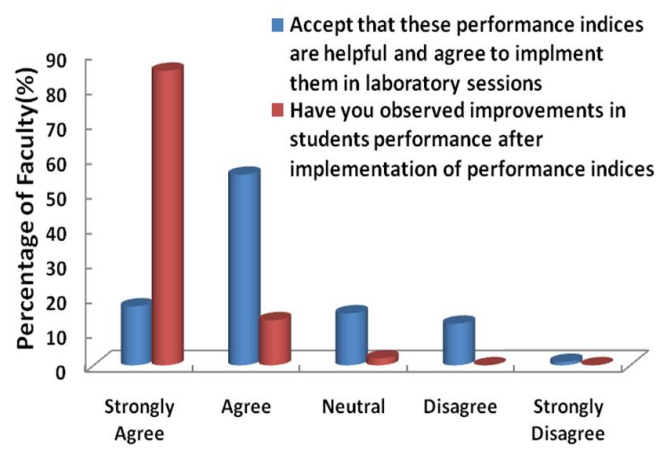

Fig. 7: Faculty feedback about use of performance indices in laboratory sessions

\section{Key Recommendations:}

The key recommendations arising from this implementation are:

1. Train and manage lab resource properly

2. Conduct interesting pre-practical activities

3. Provide online and offline learning material

4. Encourage preparedness for practical sessions

5. Harness technology to engage students

6. Encourage culture of feedback and device innovative feedback mechanisms

7. Device novel assessment techniques

8. Focus on skills resulting in increased employability

9. Encourage independent research based projects

10. Give challenging problems to the students to design experiments

11. Take care of differently abled students

Table I. Rubrics used for laboratory session

\begin{tabular}{|c|c|c|c|c|}
\hline \multicolumn{2}{|c|}{$\begin{array}{l}\text { Performance } \\
\text { Indicator }\end{array}$} & \multirow{2}{*}{$\begin{array}{l}\text { Exceed Expectation (EE) (5) } \\
\text { Awareness about experiment to be } \\
\text { performed, Knows the basic theory, } \\
\text { Circuit diagram and availability of the } \\
\text { components. Never forget to bring } \\
\text { Calculator, Semi-log paper /graph paper. } \\
\text { Seeks information from multiple sources. }\end{array}$} & \multirow{2}{*}{$\begin{array}{l}\text { Meet Expectation (ME) (3) } \\
\text { Bringing the circuit diagram and } \\
\text { material required to complete the } \\
\text { experiment but unable to explain } \\
\text { the circuit diagram. Seeks } \\
\text { information from few sources } \\
\text { mainly textbook. }\end{array}$} & \multirow{2}{*}{$\begin{array}{l}\text { Below Expectation (BE) (1) } \\
\text { Not aware of the experiment to } \\
\text { be performed. Unable to perform } \\
\text { independently. Seeks no extra } \\
\text { information other than what is } \\
\text { provided by instructor. }\end{array}$} \\
\hline PI1 & $\begin{array}{l}\text { Preparednes } \\
s\end{array}$ & & & \\
\hline PI2 & $\begin{array}{l}\text { Tool } \\
\text { selection }\end{array}$ & $\begin{array}{l}\text { Can select appropriate equipments and } \\
\text { instruments to perform investigation. }\end{array}$ & 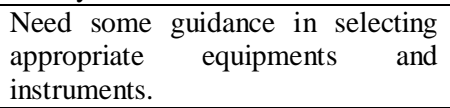 & $\begin{array}{l}\text { Cannot select, or expect others } \\
\text { to identify equipments and } \\
\text { instruments for investigation. }\end{array}$ \\
\hline PI3 & $\begin{array}{l}\text { Tool } \\
\text { operation }\end{array}$ & $\begin{array}{l}\text { Able to operate instrument and equipment. } \\
\text { Before connecting the circuit always } \\
\text { ensures the specifications. Instead of } \\
\text { replacing the equipment always tries to } \\
\text { troubleshoot the connection. }\end{array}$ & $\begin{array}{l}\text { Tentative in operation of } \\
\text { instruments and equipments. Before } \\
\text { connecting instruments always } \\
\text { ensures specifications but does not } \\
\text { show interest in troubleshooting the } \\
\text { fault. }\end{array}$ & $\begin{array}{l}\text { Requires frequent supervision } \\
\text { for operation of instrument and } \\
\text { equipment. Without verifying } \\
\text { the fault location, complains } \\
\text { about non working of } \\
\text { equipment. }\end{array}$ \\
\hline PI4 & $\begin{array}{l}\text { Experimenta } \\
\text { l Procedure }\end{array}$ & $\begin{array}{l}\text { Develops and implement the most logical } \\
\text { experimental procedures. }\end{array}$ & $\begin{array}{l}\text { Experimental Procedure most often } \\
\text { followed but occasionally oversight } \\
\text { leads to loss of experimental } \\
\text { efficiency and /or loss of data. }\end{array}$ & $\begin{array}{l}\text { Doesn't follow the experimental } \\
\text { procedure. }\end{array}$ \\
\hline PI5 & $\begin{array}{l}\text { Debugging } \\
\text { capacity }\end{array}$ & $\begin{array}{l}\text { Knows how to trace circuit, measure } \\
\text { voltage at each stage. }\end{array}$ & $\begin{array}{l}\text { Not follows the sequential steps } \\
\text { while debugging the circuit. }\end{array}$ & $\begin{array}{l}\text { Not showing interest in } \\
\text { debugging circuit. Expecting to } \\
\text { get output immediately after } \\
\text { connecting the circuit. }\end{array}$ \\
\hline PI6 & Effort & $\begin{array}{l}\text { Students show patience till get desired } \\
\text { output. Ready to work even after lab } \\
\text { hour,spare time in lab in free hours or } \\
\text { lunch break. }\end{array}$ & $\begin{array}{l}\text { Not interested to work individually. } \\
\text { Support from faculty or assistant is } \\
\text { required to get desired output. }\end{array}$ & $\begin{array}{l}\text { Not showing interest if not } \\
\text { getting the desired output. }\end{array}$ \\
\hline PI7 & $\begin{array}{l}\text { Result and } \\
\text { measuremen } \\
\text { terror }\end{array}$ & $\begin{array}{l}\text { Tries to achieve the results from different } \\
\text { viewpoints. Is aware of measurement error } \\
\text { and able to account for it statistically. }\end{array}$ & $\begin{array}{l}\text { Achieve the desired results. Is } \\
\text { aware of measurement error but } \\
\text { does not account for it statistically. }\end{array}$ & $\begin{array}{l}\text { Unable to achieve the desired } \\
\text { results. Is unaware of } \\
\text { measurement error. }\end{array}$ \\
\hline PI8 & $\begin{array}{l}\text { Analysis } \\
\text { and theory } \\
\text { application }\end{array}$ & $\begin{array}{l}\text { Analyses and interpret data carefully using } \\
\text { appropriate theory. }\end{array}$ & $\begin{array}{l}\text { Apply appropriate theory to data } \\
\text { when prompted to do so, but } \\
\text { occasionally misinterpret physical } \\
\text { significance of theory. }\end{array}$ & $\begin{array}{l}\text { Makes no attempts to relate data } \\
\text { to theory. }\end{array}$ \\
\hline PI9 & $\begin{array}{l}\text { Documentati } \\
\text { on }\end{array}$ & $\begin{array}{l}\text { Lab experiment is always writing in proper } \\
\text { format for all experiments. (Experiment } \\
\text { No, Date, Objective, Apparatus with } \\
\text { specifications, software used if any) }\end{array}$ & $\begin{array}{l}\text { Most of the lab report is in format } \\
\text { but some of the formatting } \\
\text { guidelines are missed. }\end{array}$ & $\begin{array}{l}\text { Experiments not written in } \\
\text { proper format. }\end{array}$ \\
\hline $\begin{array}{l}\text { PI1 } \\
0\end{array}$ & Lab Ethics & $\begin{array}{l}\text { Punctuality, Proper use of equipment, } \\
\text { Follow procedure that accounts for safety } \\
\text { and clean-up. }\end{array}$ & $\begin{array}{l}\text { Consistently regular but sometimes } \\
\text { missed, Follows procedure of safe } \\
\text { practices but sometimes misses } \\
\text { minor safety issues and fail to } \\
\text { clean-up. }\end{array}$ & $\begin{array}{l}\text { Irregular, Fail to follow safety } \\
\text { procedure and clean up. }\end{array}$ \\
\hline
\end{tabular}




\section{Conclusion}

There are several ways to make the laboratory sessions interesting for the students. Primarily laboratory management, content development, pre and post lab sessions, use of technology and culture of feedback is the way to improve laboratory experience. Student's involvement can be improved by implementation of the appropriate Rubrics. Improvement in the learning is demonstrated through the assessment of the sample course.

\section{References}

[1] Lyle D. Feisel and Albert J. Rosa "The Role of the Laboratory in Undergraduate Engineering Education," Journal of Engineering Education, pp. 121.130, Jan 2005.

[2] Dunne Julie and Ryan Barry, "Improving the Undergraduate Laboratory Learning Experience Through Redesigned Teaching and Assessment Strategies Integrating Transferable Skills and Focusing on Feedback," Learning, Teaching \& Technology Centre, Dublin Institute of Technology, Paper 21, pp. 1-8, 2010.

[3] Alexandra Yeung, Simon M. Pyke, Manjula D. Sharma, Simon C. Barrie, Mark A. Buntine, Karen Burke Da Silva, Scott H. Kable and Kieran F. Lim, "The Advancing Science by Enhancing Learning in the Laboratory (ASELL) Project The first Australian multidisciplinary workshop," Int. Journal of Innovation in Science and Mathematics Education, Vol. 19, No. 2, pp. 51-72, 2011.

[4] Karen E. Schmahl, "Expanding the Objectives of the lab experience," Int. J. Engng Ed. Vol. 14, No. 6, pp. 419-425, Oct. 1998.

[5] Sasha Nikolic, Christian Ritz, Peter James Vial, Montserrat Ros, and David Stirling "Decoding Student Satisfaction: How to Manage and Improve the Laboratory Experience," IEEE Trans. on Education, Vol. 58, No. 3, pp. 151-158, Aug 2015.

[6] David W. Parent and Lourdes Del Rio-Parent "Introducing TCAD Tool at Graduate Level Study," IEEE Trans. on Education, Vol. 51, No. 3, pp. 331-335, Aug. 2008

[7] Vikas J. Dongre, Ramkrishna V. Yenkar, and Vijay H. Mankar "Innovative Improvements in Electronic Engineering Laboratory Education using Electronic Mini Lab (EML): A Case Study," IEEE Inter. Conf. in MOOC, Innovation and Technology in Education (MITE), pp. 37-41, 2013.

[8] Houcine Hassan, Juan-Miguel Martínez, Carlos Domínguez, Angel Perles, and José Albaladejo "Innovative Methodology to Improve the Quality of Electronic Engineering Formation Through Teaching Industrial Computer Engineering," IEEE Trans. on Education, Vol. 47, No. 4, pp. 446-452, Nov. 2004

[9] Sabih Güzelgöz and Hüseyin Arslan, "A Wireless Communications Systems Laboratory Course," IEEE Trans. on Education, Vol. 53, No. 4, pp. 532-541, Nov. 2010.

[10] Archana Mantri, Sunil Dutt, J. P. Gupta, and Madhu Chitkara, "Design and Evaluation of A PBL Based Course in Analog Electronics," IEEE Trans. on Education, Vol. 51, No. 4, pp. 432-438, Nov. 2008.

[11] David Parent, Eric Basham, Yasser Dessouky, Stacy Gleixner, Gregory Young, and Emily Allen "Improvements to a Microelectronic Design and Fabrication Course," IEEE Trans. on Education, Vol. 48, No. 3, pp. 497-503, Aug. 2005.

[12] Ronald Grundbacher, Jochen E. Hoetzel, and Christofer Hierold "MEMSlab A Practical MEMS Course for the Fabrication, Packaging, and Testing of a Single-Axis Accelerometer," IEEE Trans. on Education, Vol. 52, No. 1, pp. 82-91, Feb. 2009.

[13] Rui Hong Chu, Dylan Dah-Chuan Lu, and S. Sathiakumar "ProjectBased Lab Teaching for Power Electronics and Drives," Vol. 51, No. 1, pp. 108-113, Feb. 2008

[14] Sasha Nikolic, Christian Ritz, Peter James Vial, Montserrat Ros \& David Stirling, " Improving the Laboratory Learning Experience: A Process to Train and Manage Teaching Assistants," IEEE Trans. on Education, vol. 58, no. , pp. 151-1588, 2015.

[15] Shulamit Kotzer and Yossi Elran "Learning and teaching with Moodle-based E-learning environments, combining learning skills and content in the fields of Math and Science \& Technology," $1^{\text {st }}$
Moodle Research Conference, Heraklion, Crete-Greece pp. 122-131, Sep. 2012.

[16] Marie Avegail M. Dolleton "MOODLE An Innovative Teaching Learning Strategy Among SISC College Students in Science Psychology and Nursing Subjects," SISC Kaizen pp. 1-39, 2011.

[17] José M. de la Rosa "Using nanoHUB org for Teaching and Learning Nanoelectronic Devices in Materials Engineering: A Simulationbased Educational Approach to the Study of Carbon Nanotubes," in IEEE Global Engineering Education Conference (EDUCON), pp. 14. Apr. 2012.

[18] S. Nikolic, "Training laboratory: Using online resources to enhance the laboratory learning experience," in IEEE Inter. Conf. on Teaching, Assessment and Learning for Engineering: Learning for the Future Now (TALE 2014), pp. 51-54, 2014.

[19] Luis de la Torre, Ruben Heradio, Carlos A. Jara, Jose Sanchez, Sebastian Dormido, Fernando Torres, and Francisco A. Candelas "Providing Collaborative Support to Virtual and Remote Laboratories," IEEE Trans. on Learning Technologies, Vol. 6, No. 4, pp. 312-323, Oct.-Dec. 2013.

[20] Rakhi Radhamani, Hemalatha Sasidharakurup, Dhanush Kumar, Nijin Nizar, Bipin Nair, Krishnashree Achuthan and Shyam Diwakar, "Explicit Interactions by Users Form a Critical Element in Virtual Labs Aiding Enhanced Education A Case Study from Biotechnology Virtual Labs," IEEE Sixth Inter. Conf. on Technology for Education, pp. 110-115, 2014.

[21] Balakrishnan Shankar, Sarithlal M. K., Sharat S, Joshua Freeman and Krishnashree Achuthan, "Remote triggered virtual laboratory for Hooke's law using LabVIEW," 39th Annual Conf. of the IEEE Industrial Electronics Society, IECON 2013, pp. 3729-3734, Nov. 2013.

[22] F. J. Jiménez-Leube, A. Almendra, C. González, and J. Sanz-Maudes, "Networked Implementation of An Electrical Measurement Laboratory for First Course Engineering Studies," IEEE Trans. on Education, Vol. 44, No. 4, pp. 377-383, Feb. 2001.

[23] William T. Neumann and Marvin C. Woodfill "Leveraging Student Experience with an Integrated Instructional Laboratory," IEEE Frontiers in Education Conference, pp. 1239-1242, Nov. 1997.

\section{Authors Biography}

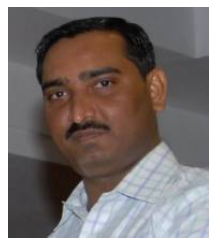

S. S. Rathod received Ph.D. from I.I.T. Roorkee $\mathrm{He}$ is Professor and Head of Electronics Engineering Department at Sardar Patel Institute of Technology Mumbai. He has 18 years of teaching experience. His special fields of interest include VLSI design, device modeling and circuit simulation. He is recognized Ph.D. guide of Mumbai University.

He has published more than 50 papers in various national and international conferences and published twenty papers in international journals like journal of applied physics, IEEE transactions on electron devices, Elsevier microelectronics reliability, IET circuit's devices and systems, ASP journal of low power electronics etc. He is reviewer of IEEE transactions on Electron Devices, Elsevier Microelectronics Journal, Microelectronics Reliability, Academic Journal of Electrical and Electronics Engineering Research, Emrald International Journal of Electronics, Journal of scientific research and review, and several national and international conferences. Three times he received best paper awards. He received outstanding achievement award (2007) by the Energy Society of India from Governor of Pondicherry. He received 'ISTE Best Engineering College Teacher Award for Maharashtra State" in year 2012. He has delivered talks at several engineering colleges on 'outcome based education'.

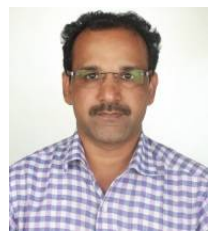

D. R. Kalbande is currently a Professor and Head in Department of Computer Engineering, Sardar Patel Institute of Technology, Andheri (West),Mumbai, India. He has completed B.E. in Computer Technology, Master of Engineering in Information Technology and obtained Ph.D from University of Mumbai, Mumbai in 2011.He has over 16+ Years experience in teaching \&research.He is recognized as Ph.D. guide in Mumbai and Nagpur University.Currently guiding 6 research scholar in the area of Soft Computing, Mobile Cloud Computing and Imaging Analysis.His area of interest is Soft Computing, Human Computing Interaction, Mobile device applications and Decision making etc.He has authored the two books namely GUI and MIS.He has delivered 
Journal of Engineering Education Transformations, Special Issue, eISSN 2394-1707

and conducted the workshop plus seminar talk on Neural Network \&

Fuzzy Logic, dot Net. Outcome based accreditation process for

Engineering Institutes.He has more than 42 papers published in

International conference and journals. 